Koryo Nakayama*, Go Ichikawa, Junko Naganuma, Satomi Koyama, Osamu Arisaka, Toshimi Sairenchi, Gen Kobashi and Shigemi Yoshihara

\title{
Adiposity rebound in very-low-birth-weight infants
}

https://doi.org/10.1515/jpem-2021-0333

Received May 12, 2021; accepted November 10, 2021;

published online November 30, 2021

\section{Abstract}

Objectives: Adiposity rebound (AR) refers to an increase in body mass index (BMI) after a nadir. Early AR, in which AR occurs earlier than five years old, is a risk factor for future obesity and metabolic syndrome, but has not been widely studied in very-low-birth-weight infants (VLBWIs). Methods: The subjects were VLBWIs born in Dokkyo Medical University NICU from January 2008 to December 2010. Height and weight measured at birth and at intervals until seven years old were obtained from medical records. The lowest BMI after one year of age was used for the age of $A R$. The subjects were divided into those with early and normal AR ( $<5$ and $\geq 5$ years old). BMI percentile at age seven years was compared using the interquartile range (IQR). Changes in BMI were evaluated by repeated measures analysis of variance (ANOVA).

Results: There were 38 early AR cases and 62 normal AR cases, giving a prevalence of early AR similar to that in infants with normal birth weight. BMI percentile at age seven years was significantly higher in early AR cases than in normal AR cases (44.6 [IQR: 21.0-79.2] vs. 14.4 [IQR: $\left.3.8-40.8] \mathrm{kg} / \mathrm{m}^{2}\right)$. Changes in BMI were also significantly higher in early AR cases ( $\mathrm{p}=0.024$ by ANOVA).

Conclusions: Early AR in VLBWIs is a predictor of future obesity.

\footnotetext{
*Corresponding author: Koryo Nakayama, Department of Pediatrics, Dokkyo Medical University School of Medicine, 880 Kitakobayashi, Mibu, Shimotsuga, Tochigi, 321-0293, Japan,

E-mail: nakayama@dokkyomed.ac.jp

Go Ichikawa, Junko Naganuma, Satomi Koyama and Shigemi Yoshihara, Department of Pediatrics, Dokkyo Medical University School of Medicine, Shimotsuga, Tochigi, Japan

Osamu Arisaka, Department of Pediatrics, Nasu Red Cross Hospital, Ohtawara, Tochigi, Japan

Toshimi Sairenchi, Center for Research Collaboration and Support, Comprehensive Research Facilities for Advanced Medical Science, Dokkyo Medical University, Mibu, Tochigi, Japan

Gen Kobashi, Department of Public Health, Dokkyo Medical University, Mibu, Tochigi, Japan
}

Keywords: adiposity rebound; pediatric obesity; very-lowbirth-weight-infants (VLBWIs).

\section{Introduction}

Children born with a low birth weight have associated increased morbidity of obesity and noncommunicable diseases, such as coronary heart disease and type 2 diabetes [1-4]. However, it is unknown if very-low-birth-weight infants (VLBWIs) have similar risks. Adiposity rebound (AR) refers to a change in body mass index (BMI) from low to high in early childhood [5]. In most children, this event occurs at age 5-7 years old. Early AR is defined as AR at less than five years, and children with early AR are more likely to develop obesity, metabolic syndrome, and type 2 diabetes in childhood and adulthood [6-10].

Few studies have examined the role of AR in childhood development in VLBWIs. Some VLBWIs are also small-forgestational age (SGA) and have extrauterine growth restriction (EUGR), depending on the pregnancy course and factors in the infants. Consequently, verifying the importance of AR in VLBWIs is challenging. Here, we examined the period in which AR occurs in VLBWIs and determined if early AR also leads to obesity in these infants, as found in infants with a normal birth weight.

\section{Methods}

The subjects were VLBWIs hospitalized in the NICU at Dokkyo Medical University Hospital from January 1, 2008 to December 31, 2010 who met the following criteria: (1) VLBWI : birth weight less than 1500 g. (2) Height and weight measured at birth and at ages 1 and 1.5 , yearly from 2 to 7 years, and beyond seven years. Infants aged $>2$ and $>5$ years with no data at $>1.5$ and $>2.5$ years, respectively, after the previous measurement were dropped from the study. (3) Gestation period determined at a pregnancy check by an obstetrician before labor pain or amniorrhexis.

Data for body weight (BW), body length (BL), gestational period (weeks), Apgar score at $5 \mathrm{~min}$, and smoking history of parents were collected from medical records.

\section{Physical measurements}

BW at each age, including at birth, was measured using a scale. BL at birth and at six months, one year, and 1.5 years of age was defined as 
the crown-to-heel length determined using a measuring tape or ruler by midwives or trained nurses. Height at two years of age was measured to the nearest $0.1 \mathrm{~cm}$ using a stadiometer by trained nurses. BMI was calculated as BW $[\mathrm{kg}] /(\text { height }[\mathrm{m}])^{2}$. Data were analyzed using Anthropometric Indices Calculation File ver. 3.0 (Microsoft Excel) edited by the joint committee for standard values of the Japanese Society for Pediatric Endocrinology and the Japanese Association for Human Auxology, and Calculation Software for Anthropometric Indices at Birth by Gestational Period ver. 1.0 (Microsoft Excel).

\section{Definitions of adiposity rebound, obesity, and overweight}

Kroke et al. [11] suggested that an estimate based on a visual estimation of the nadir in the BMI curve most directly reflects age at AR. Therefore, we defined the age at which the lowest BMI was recorded after one year of age as the timing of AR. Early AR was defined as that occurring at age $<5$ years [6-10]. Normal AR was defined as AR at age $\geqq 5$ years. Obesity was defined as BMI $>95$ th percentile and overweight as $\geq 85$ th percentile, using age- and sex-specific percentiles for children aged 2 to 19 [12].

\section{Statistical analysis}

Statistical analysis was conducted using $\mathrm{IBM}^{\circledR} \operatorname{SPSS}^{\circledR}$ ver. 26. A chisquare test was used for comparison of data in the early and normal AR groups. The IQRs of BMI percentiles at age seven in the two groups were represented as box plots and compared by Mann-Whitney U test. BMI until age 11 years was evaluated by repeated measures ANOVA to examine interactions associated with changes in BMI.

\section{Results}

\section{Subjects}

Of the 100 infants meeting the inclusion criteria, 38 were assigned to the early AR group and 62 to the normal AR group. The gender, birth weight and gestational age of the subjects are shown in Table 1. Early AR had no significant correlation with BW at birth $(\mathrm{p}=0.58)$ or gestation period $(\mathrm{p}=0.914)$. There was no significant difference in gender $(\mathrm{p}=0.063)$, but there were more male infants in the normal AR group.

BMI percentile distributions at age seven are shown Figure 1, after exclusion of subjects with missing data at age seven. A total of 35 subjects in the early AR group and 59 in the normal AR group had BMI data at age seven. BMI percentile was significantly higher in the early AR group compared to the normal AR group (44.6 [IQR: 21.0-79.2] vs. 14.4 [IQR: $\left.3.8-40.8] \mathrm{kg} / \mathrm{m}^{2}, \mathrm{p}<0.001\right)$. Obesity at age seven was found in 5 children (14.3\%) in the early AR group and $0(0 \%)$ in the normal AR group.
Table 1: Backgrounds of subjects in the early and normal AR groups.

\begin{tabular}{lrrr}
\hline Variable & Early AR $(\mathrm{n}=\mathbf{3 8})$ & Normal AR $(\mathrm{n}=62)$ & $\mathrm{p}$-Value \\
\hline Male, \% & $17(45 \%)$ & $40(65 \%)$ & 0.063 \\
Body weight (g) at birth & 3 & 3 & \\
$\leq 500 \mathrm{~g}$ & 20 & 20 & 0.58 \\
$500-1,000 \mathrm{~g}$ & 15 & 25 & \\
$1,000-1,500 \mathrm{~g}$ & & & \\
Gestation period, weeks & 20 & 30 & \\
$\leq 27$ & 15 & 27 & 0.914 \\
$28-32$ & 3 & 5 & \\
$\geq 32$ & & & \\
\end{tabular}

Mean BMI by age in the early and normal AR groups with 95\% confidence intervals are shown in Figure 2. Increased BMI occurred after AR in both groups. A repeated measures ANOVA for BMI until age 11 years in the two groups with a Greenhouse-Geisser correction gave $\mathrm{p}=0.024$ $(<0.05)$ for an intersubject test, revealing a significant interaction. Changes in mean BMI also differed between the two groups.

\section{Discussion}

This is the first report worldwide showing directly that early AR is a risk factor for obesity in VLBWIs. The major points to emerge from the study are the prevalence of early AR of 38\% in VLBWIs, and the higher rate of VLBWIs with early AR who were overweight (BMI percentile $\geq 85$ ) at age seven years.

Early AR in normal-birth-weight infants (NBWIs) has been reported to occur at rates of 27 and 47\% [6, 13, 14]. Therefore, the rate of early AR in VLBWIs seems to be similar to or higher than that in NBWIs. After AR in VLBWIs [2], BMI increased without a decrease. A repeated measures ANOVA showed a significantly greater BMI increase in early AR cases than in normal AR cases, which indicates that early AR is a predictor of an increased BMI in VLBWIs, as also found in NBWIs. There is no consensus on the influence of body composition on $A R$, but AR is affected by both lean body mass and fat mass $[15,16]$. The body composition of preterm and low-birth-weight (LBW) infants has less lean body mass, including muscles, but higher body fat [16]. This may account for the possibly higher incidence of early AR in VLBWIs compared to NBWIs.

In a longitudinal study of growth of VLBWIs, Hack et al. showed that mean BMI in males and females was lower 

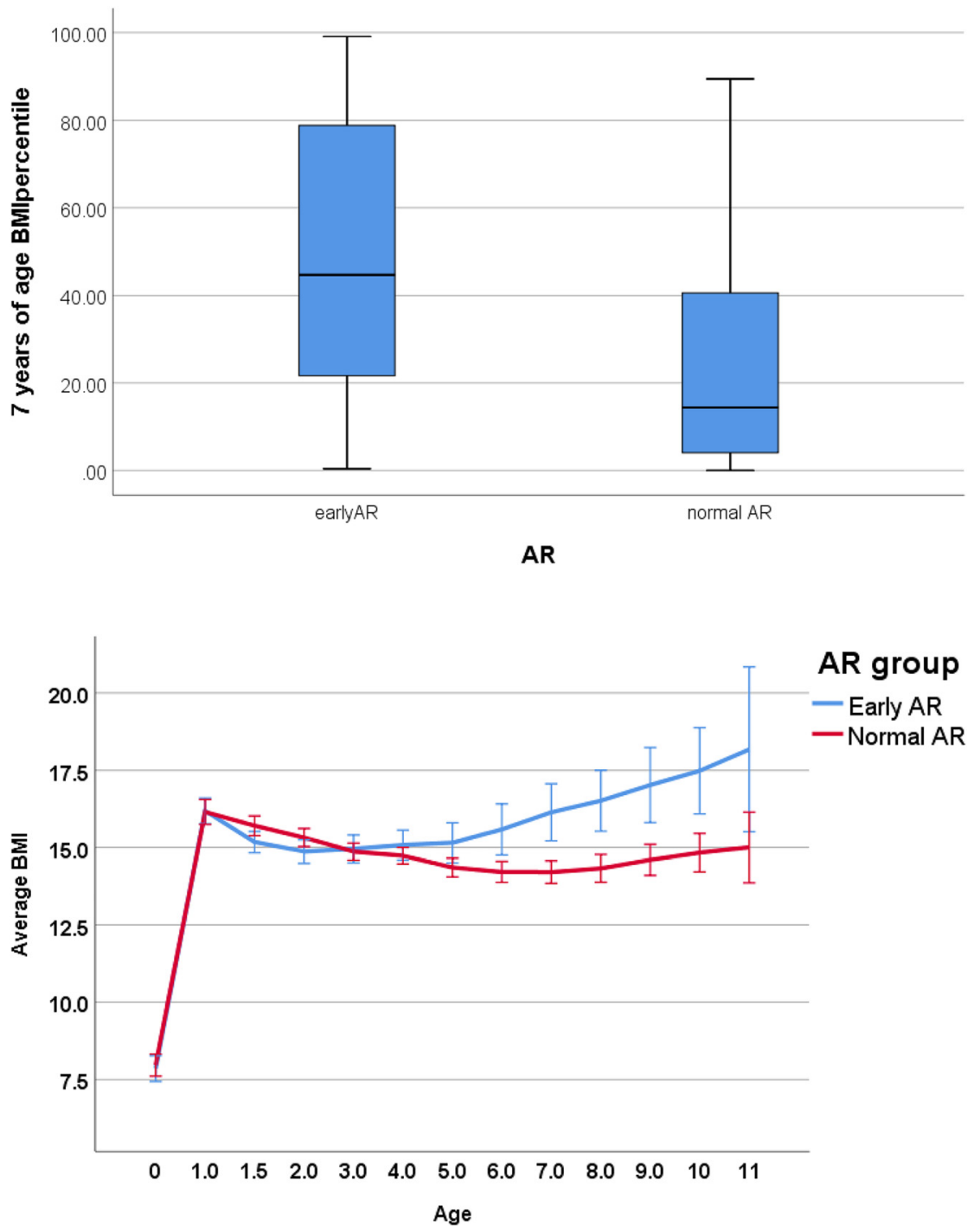

Figure 1: Rates of overweight subjects at age seven years in the early and normal AR groups. The longitudinal axis shows the BMI percentile. AR, adiposity rebound.

Figure 2: Changes in mean BMI in the early and normal AR groups. AR, adiposity rebound.

than that in NBWIs. The rates of obesity $\left(\mathrm{BMI}>30 \mathrm{~kg} / \mathrm{m}^{2}\right)$ in VLBWIs at age 20 were $7 \%$ (vs. 15\% in NBWIs) in males and $15 \%$ (vs. 18\%) in females [17]. The high rate of obesity or overweight status (BMI $>85$ th percentile) at age seven in infants with early AR in this study indicates that early AR is also a predictor of obesity in VLBWIs. EUGR is common in VLBWIs [18] and many infants then show catch-up growth [19]. EUGR is considered to have a negative effect on future metabolic abnormality [20], whereas the effect of catch-up growth remains to be assessed [21-23]. Since the effect of AR in VLBWIs was similar to that in NBWIs, there is a need to evaluate the effects of EUGR and catch-up growth on the timing of AR and the relationship of early AR with obesity at school-age and in adulthood.

The limitations of the study include its small scale and single center design, and a lack of results to examine confounding factors, including intravenous feeding after birth, caloric intake and duration, breast feeding and maternal BMI. However, this is the first study showing that early AR occurs in VLBWIs is a risk factor for obesity in VLBWIs. These findings indicate the need to establish appropriate nutrition for VLBWIs earlier after birth and to evaluate catch-up growth.

Acknowledgments: None declared.

Research funding: None declared.

Author contributions: All authors have accepted responsibility for the entire content of this manuscript and approved its submission.

Competing interests: Authors state no conflict of interest. Informed consent: Informed consent was obtained from all individuals included in this study.

Ethical approval: The local Institutional Review Board deemed the study exempt from review. 


\section{References}

1. Feng C, Osgood ND, Dyck RF. Low birth weight, cumulative obesity dose, and the risk of incident type 2 diabetes. J Diabetes Res 2018;2018:1-9.

2. Jornayvaz FR, Vollenweider P, Bochud M, Mooser V, Waeber G, Marques-Vidal P. Low birth weight leads to obesity, diabetes and increased leptin levels in adults: the CoLaus study. Cardiovasc Diabetol 2016;15:73.

3. Newton KP, Feldman HS, Chambers CD, Wilson L, Behling C, Clark $J M$, et al. Low and high birth weights are risk factors for nonalcoholic fatty liver disease in children. J Pediatr 2017;187:141-6.e1.

4. Barker DJP, Osmond C, Forsén TJ, Kajantie E, Eriksson JG. Trajectories of growth among children who have coronary events as adults. N Engl J Med 2005;353:1802-9.

5. Rolland-Cachera MF, Deheeger M, Bellisle F, Sempé M, GuilloudBataille M, Patois E. Adiposity rebound in children: a simple indicator for predicting obesity. Am J Clin Nutr 1984;39:129-35.

6. Koyama S, Ichikawa G, Kojima M, Shimura N, Sairenchi T, Arisaka 0 . Adiposity rebound and the development of metabolic syndrome. Pediatrics 2014;133:e114-9.

7. Rolland-Cachera MF, Deheeger M, Maillot M, Bellisle F. Early adiposity rebound: causes and consequences for obesity in children and adults. Int J Obes (Lond) 2006;30:S11-7.

8. Eriksson JG, Forsén T, Tuomilehto J, Osmond C, Barker DJP. Early adiposity rebound in childhood and risk of type 2 diabetes in adult life. Diabetologia 2003;46:190-4.

9. Taylor RW, Grant AM, Goulding A, Williams SM. Early adiposity rebound: review of papers linking this to subsequent obesity in children and adults. Curr Opin Clin Nutr Metab Care 2005;8:607-12.

10. Ichikawa G. Persistence of obesity from early childhood onward. N Engl J Med 2019;380:193-5.

11. Kroke A, Hahn S, Buyken AE, Liese AD. A comparative evaluation of two different approaches to estimating age at adiposity rebound. Int J Obes (Lond) 2006;30:261-6.

12. Whitlock EP, Williams SB, Gold R, Smith PR, Shipman SA. Screening and interventions for childhood overweight: a summary of evidence for the US Preventive Services Task Force. Pediatrics 2005;116:e125-44.
13. Péneau S, González-Carrascosa R, Gusto G, Goxe D, Lantieri O, Fezeu L, et al. Age at adiposity rebound: determinants and association with nutritional status and the metabolic syndrome at adulthood. Int J Obes (Lond) 2016;40:1150-6.

14. Hughes AR, Sherriff A, Ness AR, Reilly JJ. Timing of adiposity rebound and adiposity in adolescence. Pediatrics 2014;134: e1354-61.

15. Taylor RW, Williams SM, Carter PJ, Goulding A, Gerrard DF, Taylor BJ. Changes in fat mass and fat-free mass during the adiposity rebound: FLAME study. Int J Pediatr Obes 2011;6: e243-51.

16. Taylor RW, Goulding A, Lewis-Barned NJ, Williams SM. Rate of fat gain is faster in girls undergoing early adiposity rebound. Obes Res 2004;12:1228-30.

17. Nedelec R, Jokelainen J, Miettunen J, Ruokonen A, Herzig KH, Männikkö $M$, et al. Early determinants of metabolically healthy obesity in young adults: study of the Northern Finland Birth Cohort 1966. Int J Obes (Lond) 2018;42:1704-14.

18. Clark RH, Thomas P, Peabody J. Extrauterine growth restriction remains a serious problem in prematurely born neonates. Pediatrics 2003;111:986-90.

19. Maeyama K, Morioka I, Iwatani S, Fukushima S, Kurokawa D, Yamana K, et al. Gestational age-dependency of height and body mass index trajectories during the first 3 years in Japanese smallfor-gestational age children. Sci Rep 2016;6:38659.

20. Ortiz-Espejo M, Pérez-Navero JL, Olza J, Muñoz-Villanueva MC, Aguilera CM, Gil-Campos M. Changes in plasma adipokines in prepubertal children with a history of extrauterine growth restriction. Nutrition 2013;29:1321-5.

21. Singhal A. Long-term adverse effects of early growth acceleration or catch-up growth. Ann Nutr Metab 2017;70:236-40.

22. Martin A, Connelly A, Bland RM, Reilly JJ. Health impact of catchup growth in low-birth weight infants: systematic review, evidence appraisal, and meta-analysis. Matern Child Nutr 2017; 13. https://doi.org/10.1111/mcn.12297.

23. Raaijmakers A, Jacobs L, Rayyan M, Ortibus E, Levtchenko E, Staessen JA, et al. Catch-up growth in the first two years of life in Extremely Low Birth Weight (ELBW) infants is associated with lower body fat in young adolescence. PLoS One 2017;12: e0173349. 